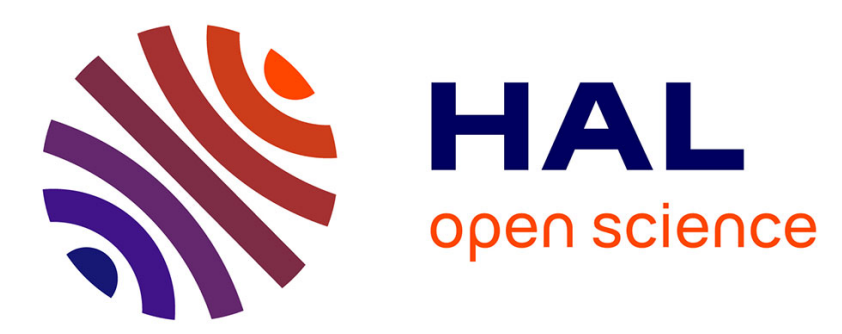

\title{
Distribution of metal nanoparticles in a plasma polymer matrix according to the structure of the polymer and the nature of the metal
}

\author{
Ali Mansour, Fabienne Poncin-Epaillard, Dominique Debarnot
}

\section{- To cite this version:}

Ali Mansour, Fabienne Poncin-Epaillard, Dominique Debarnot. Distribution of metal nanoparticles in a plasma polymer matrix according to the structure of the polymer and the nature of the metal. Thin Solid Films, 2019, 699, pp.137261. 10.1016/j.tsf.2019.04.036 . hal-03016370

\author{
HAL Id: hal-03016370 \\ https://hal.science/hal-03016370
}

Submitted on 20 Nov 2020

HAL is a multi-disciplinary open access archive for the deposit and dissemination of scientific research documents, whether they are published or not. The documents may come from teaching and research institutions in France or abroad, or from public or private research centers.
L'archive ouverte pluridisciplinaire $\mathbf{H A L}$, est destinée au dépôt et à la diffusion de documents scientifiques de niveau recherche, publiés ou non, émanant des établissements d'enseignement et de recherche français ou étrangers, des laboratoires publics ou privés. 


\title{
Distribution of metal nanoparticles in a plasma polymer matrix according to the structure of the polymer and the nature of the metal
}

\author{
A. Mansour, F. Poncin-Epaillard, D. Debarnot* \\ Institut des Molécules et Matériaux du Mans (IMMM) - UMR 6283 CNRS, Le Mans \\ Université, Avenue Olivier Messiaen, 72085 Le Mans Cedex 9, France
}

*Corresponding author: Dominique.Debarnot@univ-lemans.fr

Thin Solid films, 699, 137261 (2020)

\section{$\underline{\text { Abstract }}$}

The amount and distribution of metal nanoparticles in a plasma polymer matrix are studied according to the chemical structure of the polymer and the nature of the metal. The structure of the polymer (polyallylalcohol) is modified by varying the plasma parameters such as polymerization time, input power and discharge time. Three metals are studied: $\mathrm{Ag}, \mathrm{Cu}$ and $\mathrm{Sn}$. When the polymer contains a lot of functional groups (here hydroxyl groups) with a rough surface, a high amount of metal, homogeneously distributed is inserted into the polymer. Moreover, a higher quantity of silver and tin ions is inserted into the matrix compared to copper. Finally, two routes for the incorporation of metal nanoparticles are studied where the impregnation with metallic salts and their reduction are done either in two stages or in one-step with a single solution containing both the metallic salt and the reducing agent. The first method allows obtaining a higher amount of loaded metal with a homogeneous dispersion in the matrix.

Keywords: polymer/metal nanocomposites; plasma polymer; metal distribution.

\section{Introduction}


Nowadays, plasma polymer nanocomposites consisting of finely dispersed metal nanoparticles into insulating matrix are the focus of much attention because of their specific microstructural, optical and electrical properties allowing a variety of technological applications. Polymers are particularly attractive as dielectric matrices. They are generally low-cost materials, versatile, and can easily be processed into thin films.

A wide range of methods for the synthesis of polymer / metal composites have been reported. Several methods in gas phase have been employed such as the plasma polymerization of organometallic precursors, ${ }^{1}$ simultaneous evaporation of metal and polymer or combination of plasma polymerization and metal particle deposition using sputtering from a target ${ }^{2,3}$ or metal evaporation. ${ }^{4,5}$ Other synthesis methods take place in solution through two routes. ${ }^{6}$ One of them consists in depositing the polymer film onto the substrate from a solution; the metal precursor (typically a metal salt) is then introduced into it using metal precursor solution or vapour. In the other way, the polymer and precursor are mixed in solution and deposited onto the substrate. For these two methods, the metal nanoparticles are then in-situ generated using chemical reduction $^{7}$ or physical methods such as photoirradiation ${ }^{8,9}$ or thermal treatment ${ }^{10,11}$. The aqueous solution reduction is widely used because of its simplicity. In our work, we combine the synthesis of the polymer by plasma polymerization followed by the insertion of metal particles by dipping it in a metal salt aqueous solution for at the end be chemically reduced. Some studies have adopted this process of synthesis of composite materials, but they mainly focus on the applications of polymer/metal composites. For example, it has been reported the generation of many antibacterial coatings involving plasma polymerization of monomers and in situ synthesis of silver nanoparticles within the polymer films by the chemical reduction of $\mathrm{Ag}^{+}$using $\mathrm{NaBH}_{4} .^{12,13,14}$

Here, in this study, our goal is to study the dependence of chemical and morphological properties of such composite materials on the chemical structure of the plasma polymer and the 
nature of the metal nanoparticles. The objective is to better understand the nanocomposites formation. Plasma-polymerized allyl alcohol (pp-AAl) has been chosen as polymer matrix and silver, copper and tin as metal nanoparticles.

\section{Experimental}

\subsection{Materials and methods}

Allyl alcohol monomer (mol. wt $=58.08 \mathrm{~g} \mathrm{~mol}^{-1}$, purity $\geq 98.5 \%$, Sigma-Aldrich) was used as received. The three metallic powders: $\mathrm{AgNO}_{3}$ (mol. wt $=169.87$ g.mol ${ }^{-1}$, Fisher), $\mathrm{Cu}\left(\mathrm{NO}_{3}\right)_{2} \cdot 2.5 \mathrm{H}_{2} \mathrm{O}\left(\mathrm{mol} . \mathrm{wt}=232,59 \mathrm{~g} \cdot \mathrm{mol}^{-1}\right.$, purity $=99.99 \%$, Aldrich $)$ and $\mathrm{SnCl}_{2} .2 \mathrm{H}_{2} \mathrm{O}(\mathrm{mol}$. $\mathrm{wt}=225.65 \mathrm{~g} \cdot \mathrm{mol}^{-1}$, purity $=96 \%$, Sigma Aldrich) were used without further purification for the preparation of the aqueous metallic solutions. $\mathrm{NaBH}_{4}$ (mol. wt $=37.83$ g. $\mathrm{mol}^{-1}$, purity $=$ 96\%, Sigma Aldrich) was used as the reducing agent and doubly distilled water (Millipore, resistivity $18 \mathrm{M} \Omega . \mathrm{cm}$ ) was utilized for preparing all solutions.

\subsection{Deposition of plasma-polymerized allyl alcohol (pp-AAI)}

The reactor consists of a cylindrical aluminum capacitively coupled chamber with two parallel circular electrodes. The monomer vapour was introduced into the reactor from a glass container with the liquid monomer. An argon (Ar) plasma was used before the polymerization process under these conditions ( $P=100 \mathrm{~W}, F=10 \mathrm{sccm}, t=1 \mathrm{~min}$ ) for adhesion improvement on all the substrates (glass slides, silicon ( $\mathrm{Si}$ ), and polypropylene (PP)). This treatment was performed to clean the substrates of molecular level contaminants and to increase the roughness of the substrates. As an example, for the silicon substrate, the values of the roughness Ra determined by AFM before and after Ar plasma treatment are $0.76 \pm 0.1 \mathrm{~nm}$ and $1.4 \pm 0.1 \mathrm{~nm}$ respectively. Consequently, pp-AAl layer has good adhesion onto the substrate. ${ }^{15,16}$ 
In this work, pp-AAl has been synthesized under different power (30 $\mathrm{W}$ or $70 \mathrm{~W}$ ), pulse ontime (ton) $(17$ or $150 \mu \mathrm{s})$ whereas pulse off-time (toff) was maintained at $17 \mu$ s for all the experiments.

\subsection{Incorporation of silver, copper and tin ions into the pp-AAl coatings}

pp-AAl, once deposited onto the substrate, was dipped into the different aqueous solutions $(0.1$ M) at room temperature. Subsequently, the reduction of the metal ions embedded in the polymer coating was initiated by dipping it into $0.1 \mathrm{M} \mathrm{NaBH}_{4}$ aqueous solution at room temperature under continuous and constant stirring in a dark place. Between each step, the composites were rinsed with distilled water and dried with air.

\subsection{Characterization techniques}

Polymer and composites were characterized using different analytical and morphological techniques.

\subsubsection{Water contact angle measurements}

Water contact angles (WCA) were measured onto the coated glass slides (Thermo scientific, Superfrost ultra plus) with a Ramé-Hart NRL goniometer instrument at room temperature. Static water contact angles goniometry was performed to get an idea about the progress of surface modification before and after addition of metallic ions. The use of water to measure the contact angle gives direct information on the hydrophobic or hydrophilic nature of the surface. Each water contact angle value is the average of at least 6 measurements corresponding to 3 different drops of a volume of $3 \mu \mathrm{L}$.

\subsubsection{X-ray photoelectron spectroscopy (XPS)}


The chemical nature of the plasma layers deposited onto silicon wafers (100) (Siltronix, France) was determined by XPS using Kratos Axis Nova instrument. The photoemission was excited by a monochromatic $\mathrm{Al} \mathrm{K \alpha}$ beam at $1486.6 \mathrm{eV}$. The narrow scans of elements were acquired with steps of $0.1 \mathrm{eV}$ and a pass energy of $40 \mathrm{eV}$. The emission was analyzed at a take-off angle of $90^{\circ}$ relative to the sample surface, yielding a sampling depth of maximal $10 \mathrm{~nm}$ due to the mean free path of the electrons. Calibration was conducted on the $\mathrm{C} 1 \mathrm{~s}$ peak of the $\mathrm{C}-\mathrm{C}$ and $\mathrm{C}$ $\mathrm{H}$ bonds at $285.0 \mathrm{eV}$. The curve fitting was performed using Casa XPS software (Casa Software Ltd.). The peak shape was chosen with Gaussian (70\%) / Lorentzian (30\%) curve fitting and quantification was reliable to $\pm 5 \%$.

\subsubsection{FTIR spectroscopy}

In this section, potassium bromide (KBr) $(99.99 \%$, Sigma-Aldrich) pellets and polypropylene (PP) (Goodfellow Production, England) were used as inorganic and organic substrates. A Bruker-vertex 70V spectrometer with a globar light source and a DTGS detector was used. The FTIR spectra were recorded in the absorbance mode in the range of 400 to $4000 \mathrm{~cm}^{-1}$ with a resolution of $2 \mathrm{~cm}^{-1}$ using 32 scans. All the $\mathrm{KBr}$ spectra were normalized with respect to thickness. The sampling depth of the spectra measured in the Attenuated Total Reflectance (ATR) technique using diamond was in the range of about $1.66 \mu \mathrm{m}$ at $1000 \mathrm{~cm}^{-1}$ and $45^{\circ}$ as angle of incidence.

\subsection{4. $U V$-vis spectroscopy}

UV-vis absorption measurements were performed using a Varian UV Spectrometer Cary 100 at room temperature, in the wavelength range of $200-900 \mathrm{~nm}$. The spectra were measured in a double beam mode, the reference was carried out with a glass slide. 


\subsubsection{Atomic force microscopy (AFM)}

AFM micrographs were obtained using microscope Bruker-Innova working in the tapping mode. Silicon wafers (100) (Siltronix, France) were used for all measurements. Typically, the surface morphology of $5 \mu \mathrm{m} \times 5 \mu \mathrm{m}$ area near the center of each sample was observed. The images were processed by the Gwiddion software for the subtraction of the polynomial background and the calculation of the average roughness (Ra). For the determination of the film thickness via AFM, the Si wafers were preventively cleaned and partially masked with an adhesive tape during the plasma deposition. Once the deposition was finished, the mask was removed and the height of the created step corresponds to the thickness of the polymer film. An average of six separate measurements was made for each sample.

\subsubsection{Transmission electron microscopy (TEM)}

TEM-micrographs (Transmission Electron Microscopy) were taken by the STEM 2100 (JEOL) operating at $200 \mathrm{kV}$. Polymer films were deposited on TEM nickel grids (Formvar/carbon film, 200 mesh, Ni, USA / Canada) in order to obtain a thickness lower than $100 \mathrm{~nm}$, then dipped in the different metallic and reducing solutions.

\section{Results and discussion}

The first part of this section is dedicated to the optimization of the metal loading into the polymer matrix through the study of the impregnation and reduction steps. In the two following parts, the objective is to evaluate if the chemical structure of the plasma-polymer or the nature of the metal influences its distribution and its embedded amount into the polymer. The chemical structure of $\mathrm{pp}-\mathrm{AAl}$ is modified by varying the plasma parameters such as polymerization time, input power and discharge time. We are interested in three metals: $\mathrm{Ag}, \mathrm{Cu}$ and $\mathrm{Sn}$ that are more or less oxidation resistant. 


\subsection{Influence of impregnation and reduction steps}

In order to study these parameters, the silver salts have been chosen since the silver nanoparticles have a strong surface plasmon resonance (SPR) band, facilitating their characterization in thin films by UV-visible spectroscopy. The SPR band position depends on the nature of the metal, its shape, size and distribution. ${ }^{17}$

In our study and as described in the experimental part, the incorporation of silver nanoparticles into pp-AAl is obtained by successively dipping the plasma polymer into the metallic salt solution and then the reducing one, with rinsing the composites with water and drying it with air between each step. However, the method generally described in the literature, so-called Borane method, consists in dipping the polymer matrix in a single solution composed of the metallic salt and an excess of the reducing agent $\left(\mathrm{NaBH}_{4}\right){ }^{18,19}$ Figure 1 presents the UV-Vis absorption spectra for bare pp-AAl and for the polymer loaded with Ag either in two steps: before (pp-AAl/Ag) and after reduction of the metallic salt (pp-AAl/Ag/NaBH 4$)$ or in one step with the Borane method (pp-AAl $\left.\left(\mathrm{Ag}+\mathrm{NaBH}_{4}\right)\right)$.

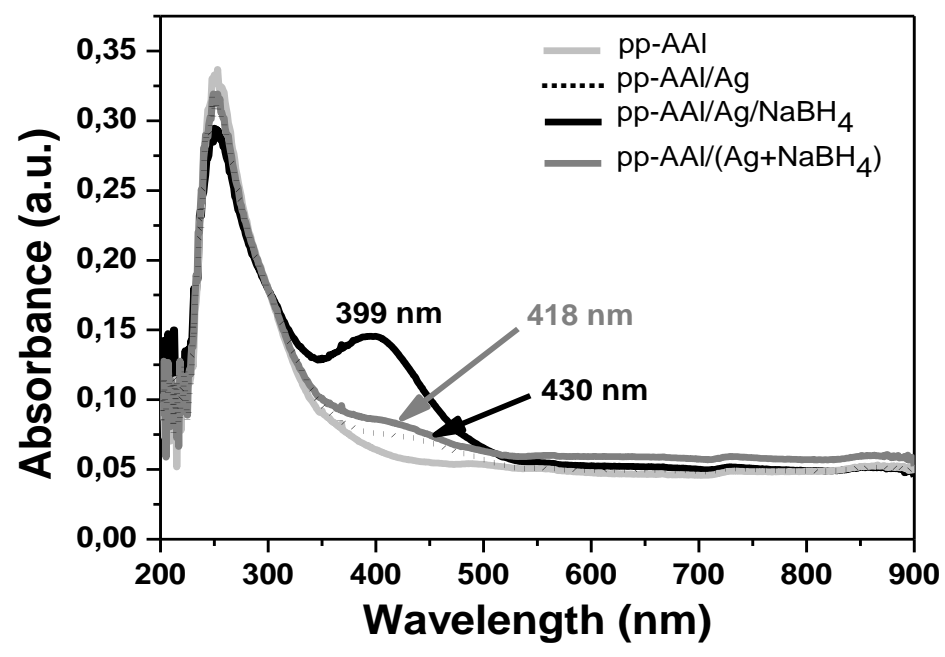

Figure 1. UV-Vis spectra of bare pp-AAl, pp-AAl/Ag (3h), pp-AAl/Ag/NaBH $(1 \mathrm{~h})$ and pp$\mathrm{AAl} /\left(\mathrm{Ag}+\mathrm{NaBH}_{4}\right) .(P=30 \mathrm{~W}, D . C .=50 \%, f=30 \mathrm{kHz}, t=20 \mathrm{~min})$. 
In the two-stage method, the appearance of a band at $399 \mathrm{~nm}$ after reduction is due to the surface plasmon absorption, showing the presence of $\mathrm{Ag}$ metallic particles $(\mathrm{Ag}(0))$ of nanometric dimensions. This position indicates the formation of crystalline Ag nanoparticles (AgNps) with a spherical shape. Before reduction, a weak absorption is observed at $430 \mathrm{~nm}$ meaning that the polymer is able to reduce the cations to their metallic form. The increase in intensity after the reduction shows its effectiveness but also the change in morphology of the layer. Indeed, Figure 2 shows the formation of more nanometer-sized particles after reduction by $\mathrm{NaBH}_{4}$. The reduction step is then necessary not only to complete the reduction of silver ions but also to give a more uniform distribution of smaller particles.

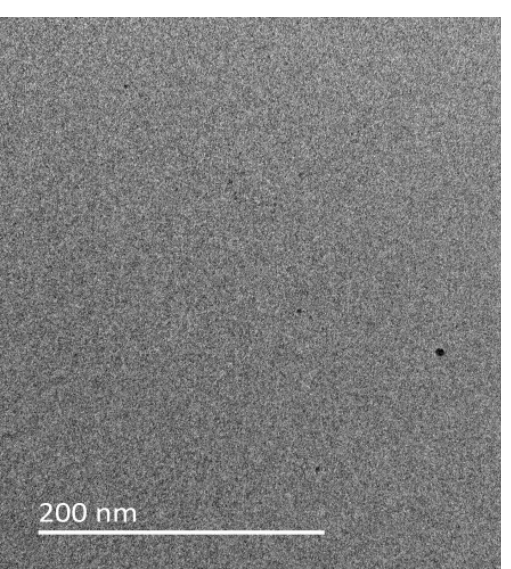

(a)

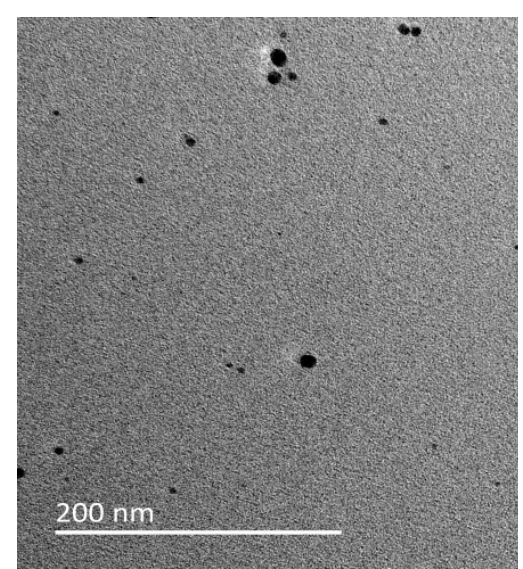

(b)

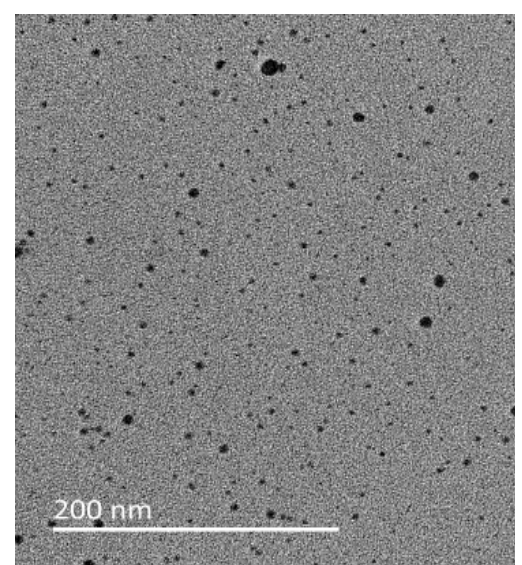

(c)

Figure 2. TEM images of (a) pp-AAl, (b) pp-AAl/AgNO 3 (c) pp-AAl/AgNO $3 / \mathrm{NaBH}_{4}$

The shift of the wavelength from $430 \mathrm{~nm}$ to $399 \mathrm{~nm}$ after reduction in UV-Vis spectra confirms the decrease in the size of the aggregates. ${ }^{20,21}$

The intensity of the SPR band is lower with the one-step process, when no washing step is realized between the impregnation and the reduction steps, proving a lower amount of added Ag in the matrix or a larger particle size. In this method, the AgNps are formed in the solution rather than in the polymer. Our result can be explained either by the absence of electrostatic 
interaction between $\mathrm{AgNps}$ and the polymer which is not favourable to the insertion of metal or by the competition between remaining $\mathrm{Ag}^{+}$ions and $\mathrm{Na}^{+}$ones for their inclusion into the polymer. Moreover, the red-shift and broadening of the absorption band of AgNPs $(\lambda=418$ $\mathrm{nm}$ ) indicate the increase in particle size and particle size distribution ${ }^{22}$ of silver particles as shown by AFM (Figure 3). The AFM images clearly show the aggregation of the metal particles with a value of Ra equals to $5.6 \pm 0.3 \mathrm{~nm}$ for the Borane method compared to $0.22 \pm 0.022 \mathrm{~nm}$ for the two-step method. The latter thus allows the formation of more homogeneous monodisperse polymer/metal structure with a high amount of metal.

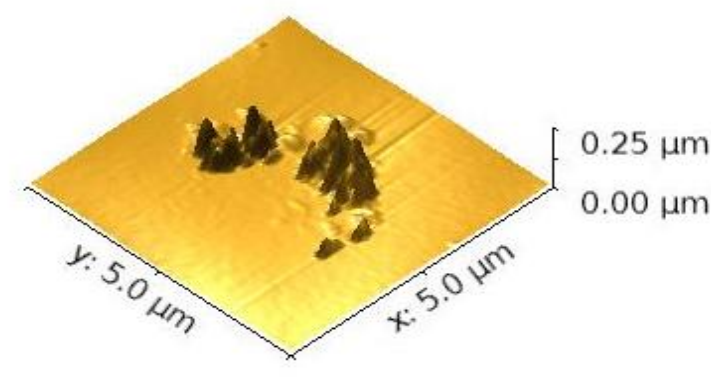

(a)

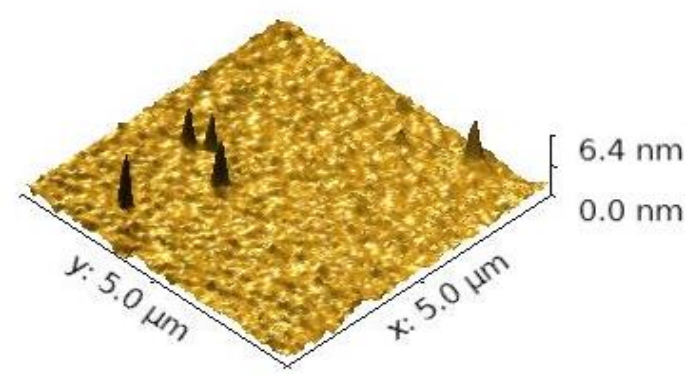

(b)

Figure 3. AFM images of pp-AAl after incorporation of Ag nanoparticles either by the onestep process (a) or by the two-step one (b).

The UV-Vis spectra present also a peak at $253 \mathrm{~nm}$ which is assigned to the $\mathrm{C}-\mathrm{O}, \mathrm{C}=\mathrm{O}$ and $\mathrm{C}=\mathrm{C}$ groups of pp-AAl. ${ }^{23}$ The decrease in intensity of this peak after the impregnation step shows that pp-AAl containing oxygen functions interacts with metal ions through favorable electrostatic interactions. The $\mathrm{Ag}^{+}$ions are bound to $\mathrm{pp}-\mathrm{AAl}$ via electrostatic interactions (iondipole), because the electron-rich oxygen atoms of polar hydroxyl are expected to interact with electropositive metal cations, thus reducing them to metallic $\mathrm{Ag}$ and forming $\mathrm{C}=\mathrm{O}$ bonds. In addition to reducing $\mathrm{Ag}^{+}$ions, $\mathrm{NaBH}_{4}$ interacts with carbonyl groups of the plasma-polymer to form $\mathrm{COO}^{-} \mathrm{Na}^{+}$groups as shown by UV-Vis and FTIR spectroscopies (Figure 4). Figure 4a shows the UV-Vis spectra of pp-AAl before and after dipping into $\mathrm{NaBH}_{4}$ solution. The 
decrease of the band intensity at $250 \mathrm{~nm}$ clearly indicates the interaction between the reducing agent and the polymer. The FTIR spectra (Figure 4b) allow establishing that the carbonyl groups of pp-AAl are involved. The assignment of the IR peaks is summarized in Figure 4b. The band between 3600 and $3000 \mathrm{~cm}^{-1}$ is classically assigned to $\mathrm{vOH}$; around $1700 \mathrm{~cm}^{-1}$ to $\mathrm{V}$ $\mathrm{C}=\mathrm{O} ; \mathrm{C}=\mathrm{C}$ at $1650 \mathrm{~cm}^{-1} ; \delta \mathrm{O}-\mathrm{H} / \mathrm{CH}_{2 \text { as }}$ at $1430 \mathrm{~cm}^{-1}$ and $\mathrm{C}-\mathrm{O}$ at $1030 \mathrm{~cm}^{-1}$. After dipping into $\mathrm{NaBH}_{4}$ solution, the $\mathrm{C}=\mathrm{O}$ band intensity decreases whereas a new band appears attributed to $\mathrm{COO}^{-} \mathrm{Na}^{+}$groups.

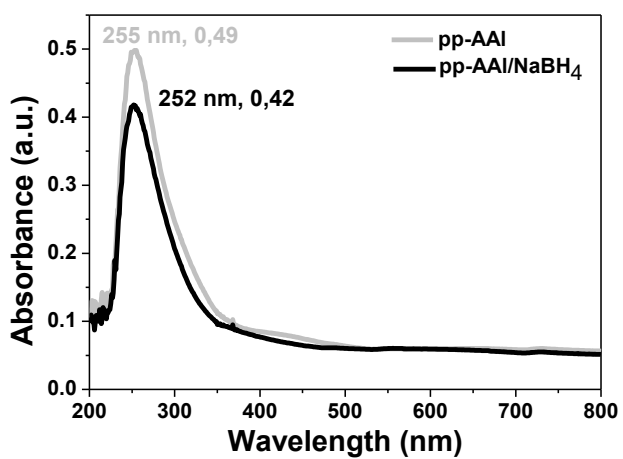

(a)

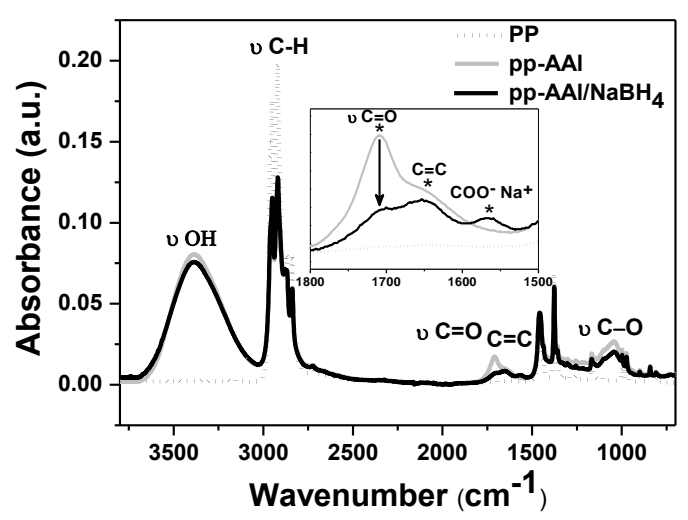

(b)

Figure 4. UV-Vis (a) and FTIR (b) spectra of pp-AAl before and after reduction by $\mathrm{NaBH}_{4}$ during $1 \mathrm{~h}$.

Figure 5a shows the influence of the impregnation time on the intensity of the AgNps SPR band before and after reduction at a fixed reduction time $(1 \mathrm{~h})$. Before the reduction $\left(\lambda_{\max }=430 \mathrm{~nm}\right)$, the SPR absorption increases slightly with the impregnation time until $2 \mathrm{~h}$. The absorption then remains constant. After reduction, the intensity of the absorption peak $(\lambda=399 \mathrm{~nm})$ seems to remain almost constant whatever is the time of impregnation. We have thus chosen to fix the impregnation time at $3 \mathrm{~h}$ for all the metallic salts ( $\mathrm{Ag}, \mathrm{Cu}$ and $\mathrm{Sn}$ salts). Regarding the effect of the reduction time (Figure 5b), a decrease of AgNPs absorption after $1 \mathrm{~h}$ is observed while maintaining a constant time of impregnation $(3 \mathrm{~h})$. After $2 \mathrm{~h}$ of reduction, the composite tends 
to delaminate from the glass slide. Following these observations, the reduction time is fixed at $1 \mathrm{~h}$ for all the metal salts.

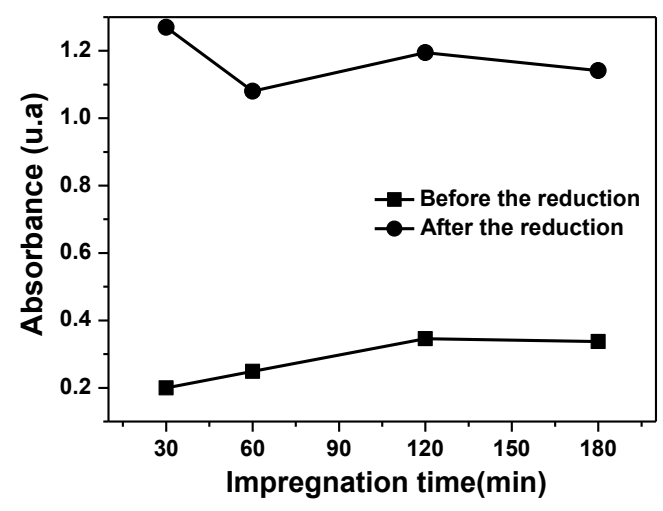

(a)

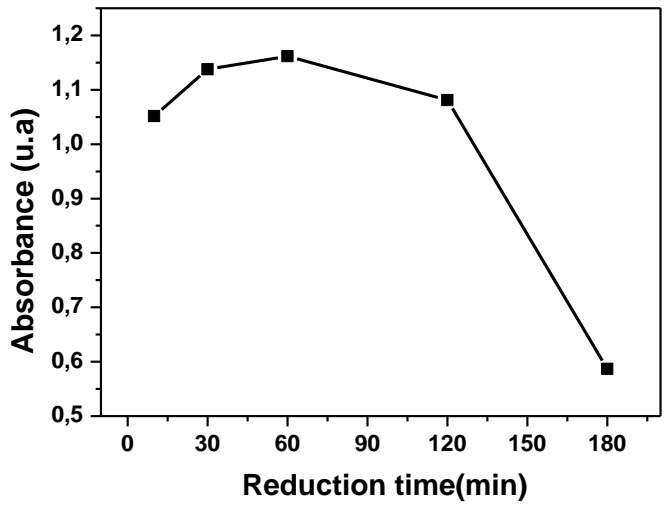

(b)

Figure 5. (a) Influence of the time of impregnation in $\mathrm{AgNO}_{3}$ before and after reduction (reduction time $=1 \mathrm{~h}$ ), (b) Influence of the time of reduction in $\mathrm{NaBH}_{4}$ after $3 \mathrm{~h}$ of impregnation $(P=30 \mathrm{~W}$, D.C. $=50 \%, f=30 \mathrm{kHz}, t=20 \mathrm{~min})$.

To investigate the ageing of the nanocomposite films under ambient atmosphere, UV-Vis spectra are measured as a function of time, as shown in Figure 6. At the initial stage of the ageing (one week), the SPR band of AgNPs shifts from $399 \mathrm{~nm}$ to $418 \mathrm{~nm}$ that can be attributed to the agglomeration of the nanoparticles. With the further ageing of the composite material, the SPR band position slowly shifts to remain constant at around $420 \mathrm{~nm}$ after around 20 days. 


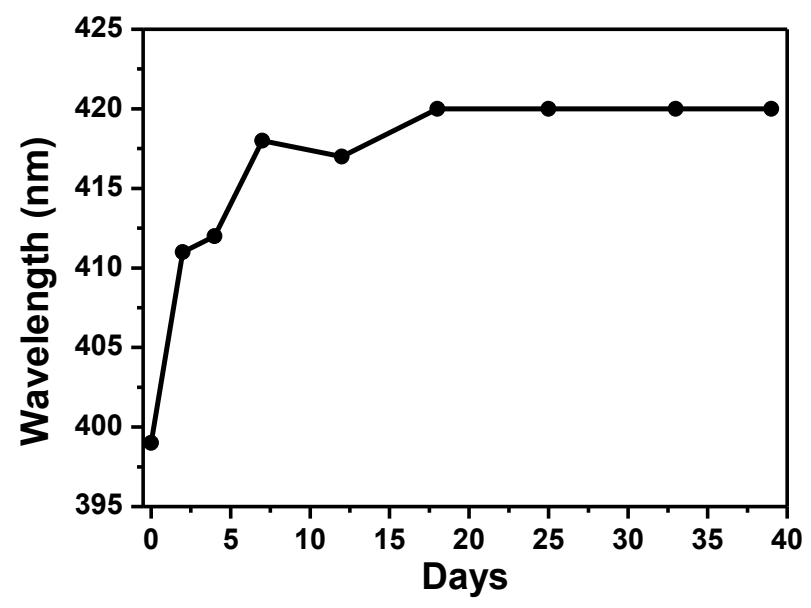

Figure 6. Ageing of the nanocomposite as a function of time under ambient atmosphere.

\subsection{Influence of the plasma parameters on the metal particles incorporation}

\subsubsection{Influence of the polymerization time}

Figure 7a shows the effect of the deposition time on the amount of loaded silver nanoparticles and on the thickness of the polymer. Increasing the polymerization time in the range 5-30 min leads not only to an increase in the thickness, but also a rapid increase in the silver concentration. Such a rise of silver concentration can be explained by the roughness increase observed when varying the polymerization time (Figure 7b). Ra values of pp-AAl synthesized at different polymerization times show their gradual increase leading to an increase in the amount of loaded silver. Indeed, Vasilev et al. ${ }^{12}$ showed that immersion of the heptylamine plasma polymer in aqueous solution leads to extraction of low-molecular-weight water-soluble fractions of the films, thus creating a nanoporous structure, which allows the loading of $\mathrm{Ag}^{+}$ ions and the subsequent formation of silver nanoparticles within the films. We can then consider that the rise of roughness allows a higher incorporation of metal into the polymer. 


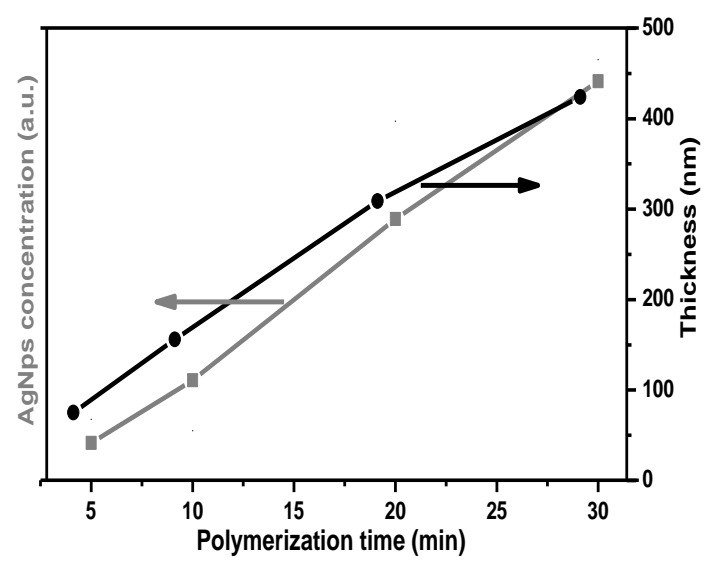

(a)

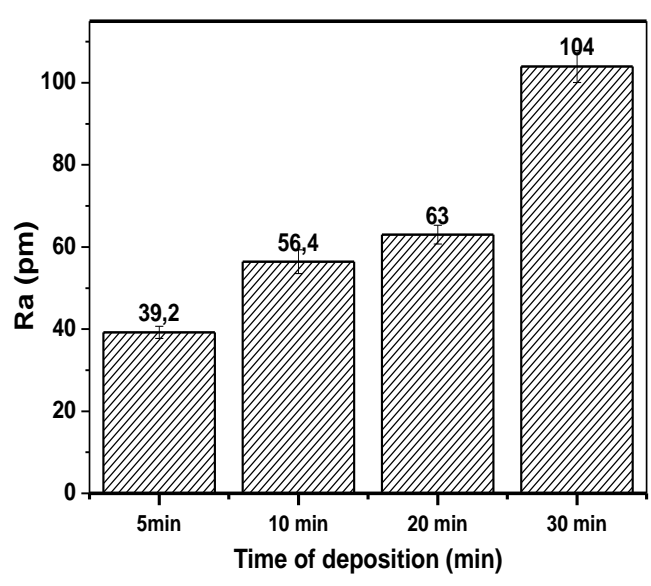

(b)

Figure 7. (a) Influence of polymerization time on the amount of loaded AgNPs, (b) Ra values of pp-AAl at different polymerization times before $\mathrm{Ag}$ impregnation.

\subsubsection{Influence of power and discharge time $\left(t_{o n}\right)$}

It is found that the increase in the input power or $t_{\text {on }}$ has a great effect on the surface hydrophilicity of the pp-AAl coatings, as the water contact angle (WCA) values increase with increasing these two parameters (Table 1). Furthermore, it is also observed that this change in hydrophilicity of pp-AAl has a strong impact on the WCA of the final composite before and after the reduction step. A significant increase in contact angle after Ag loading is observed for the most hydrophilic polymer synthesized at $P=30 \mathrm{~W}, D . C .=50 \%$ and $f=30 \mathrm{kHz}$, while this increase becomes less important when the polymer is elaborated at higher power or $t_{\text {on }}$ (Table 1). This change in WCA is related to either the chemical structure, the morphological structure of the polymer or both and which affects the final structure of the composite material. 
Table 1. Water contact angle measurements of pp-AAl and its composites at different plasma conditions.

\begin{tabular}{|c|c|}
\hline & WCA $\left(^{\circ}\right)$ \\
\hline pp-AAl $(P=30 \mathrm{~W}, f=30 \mathrm{kHz}, D . C .=50 \%$, ton $=17 \mu \mathrm{s})$ & $39.6 \pm 0.8$ \\
\hline$+\mathrm{Ag}$ & $54 \pm 1.7$ \\
\hline$+\mathrm{Ag} / \mathrm{NaBH}_{4}$ & $54.4 \pm 1.7$ \\
\hline pp-AAl $(P=70 \mathrm{~W}, f=30 \mathrm{kHz}, D . C .=50 \%$, ton $=17 \mu \mathrm{s})$ & $54.7 \pm 0.5$ \\
\hline$+\mathrm{Ag}$ & $56.3 \pm 1.1$ \\
\hline$+\mathrm{Ag} / \mathrm{NaBH}_{4}$ & $58.1 \pm 1.2$ \\
\hline pp-AAl $(P=30 \mathrm{~W}, f=6 \mathrm{kHz}, D . C .=90 \%$, ton $=150 \mu \mathrm{s})$ & $50.5 \pm 1$ \\
\hline$+\mathrm{Ag}$ & $54.8 \pm 0.9$ \\
\hline$+\mathrm{Ag} / \mathrm{NaBH}_{4}$ & $55.2 \pm 1.1$ \\
\hline
\end{tabular}

First, studying the chemical structure of polymers, we have determined by XPS the ratio of oxygen to carbon for the plasma polymers elaborated in different conditions (Table 2). When pp-AAl is elaborated at $P=30 \mathrm{~W}$, the $\mathrm{O} / \mathrm{C}$ ratio $(0.23)$ is close to the theoretical value obtained for the monomer (AAl) of 0.33 . When high powers and $t_{\text {on }}$ are used, $\mathrm{O} / \mathrm{C}$ ratios $(0.16)$ become far from the monomer value, meaning that high fragmentation of the monomer species occurs in the gas phase during plasma excitation. We can thus relate the increase of WCA with increasing the power or $t_{o n}$ to the higher fragmentation of the monomer and formation of polymers with a relatively high degree of cross-linking and low oxygen content.

Table 2. Atomic composition, $\mathrm{O}$ to $\mathrm{C}$ ratio and relative $\%$ of $\mathrm{C} 1 \mathrm{~s}$ components of pp-AAl elaborated under different conditions (XPS data). 


\begin{tabular}{|c|c|c|c|c|c|c|c|}
\hline & \multicolumn{2}{|c|}{$\begin{array}{c}\text { Atomic } \\
\text { composition }(\%)\end{array}$} & \multirow{2}{*}{$\begin{array}{c}\text { Atomic } \\
\text { ratio } \mathrm{O} / \mathrm{C}\end{array}$} & \multirow{2}{*}{$\begin{array}{c}\text { C-C, C-H, } \\
\text { C=C } \\
(\%)\end{array}$} & \multirow{2}{*}{$\begin{array}{c}\mathrm{C}-\mathrm{OH} / \mathrm{R} \\
(\%)\end{array}$} & \multirow{2}{*}{$\begin{array}{l}\mathrm{C}=\mathrm{O} \\
(\%)\end{array}$} & \multirow{2}{*}{$\begin{array}{c}\text { COOR } \\
(\%)\end{array}$} \\
\hline & $\mathrm{C}$ & $\mathbf{O}$ & & & & & \\
\hline $30 \mathrm{~W}, t_{o n}=17 \mu \mathrm{s}$ & $81.2 \pm 4$ & $18.8 \pm 0.9$ & 0.23 & 68.01 & 23.35 & 7.11 & 1.5 \\
\hline $70 \mathrm{~W}, t_{o n}=17 \mu \mathrm{s}$ & $86.5 \pm 4.3$ & $13.5 \pm 0.7$ & 0.16 & 79.59 & 13.7 & 5.4 & 1.3 \\
\hline $30 \mathrm{~W}, t_{o n}=150 \mu \mathrm{s}$ & $86.5 \pm 4.3$ & $13.5 \pm 0.7$ & 0.16 & 79.01 & 14.28 & 5.4 & 1.3 \\
\hline
\end{tabular}

Moreover, the high resolution C1s XPS spectra of pp-AAl elaborated in different conditions (Figure 8), can be decomposed in four components at (i) $285 \mathrm{eV}$ attributed to $\mathrm{C}-\mathrm{C}, \mathrm{C}-\mathrm{H}, \mathrm{C}=\mathrm{C}$; (ii) $286.4 \mathrm{eV}$ assigned to $\mathrm{C}-\mathrm{OH} / \mathrm{R}$; (iii) $287.8 \mathrm{eV}$ due to $\mathrm{C}=\mathrm{O}$ and (iv) $289.2 \mathrm{eV}$ assigned to COOR. It appears clearly that all the oxygenated groups decrease when $P$ or $t_{\text {on }}$ raises, especially the $\mathrm{C}-\mathrm{OH} / \mathrm{R}$ groups (Table 2). However, after Ag loading, the presence of $\mathrm{OH}$ functional groups enables pp-AAl to uptake a high amount of metal ions from aqueous solution and fixes them in the matrix by dipole-ion attraction. A lower hydroxyl content is then associated to a lower amount of metal particles, as proved by XPS quantification giving $0.9 \%$ of silver for $P=30 \mathrm{~W}$ and ton $=17 \mu \mathrm{s}$, and $0.2 \%$ for the other two conditions. These results thus explain the small change in WCA at high power or $t_{o n}$ after Ag loading.

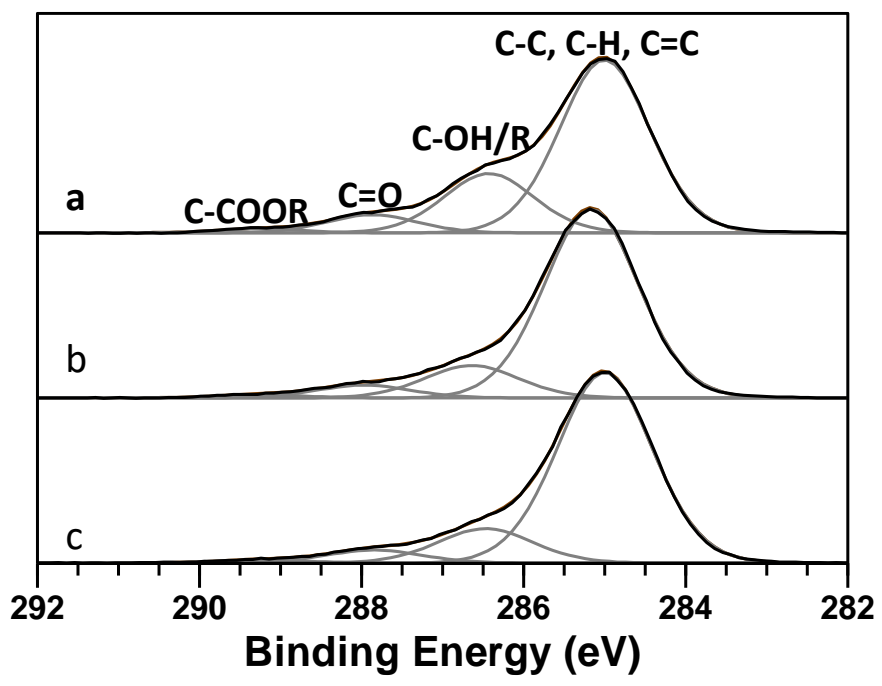

Figure 8. C1s high resolution XPS spectra of pp-AAl elaborated under different conditions: (a) $P=30 \mathrm{~W}$, ton $=17 \mu \mathrm{s}$, (b) $P=70 \mathrm{~W}$, ton $=17 \mu \mathrm{s}$, and (c) $P=30 \mathrm{~W}$, ton $=150 \mu \mathrm{s}$. 
Since the effect of the power is the same as that of the $t_{o n}$ favoring the formation of polymers with a higher degree of crosslinking when increasing one of them, ${ }^{24}$ the effect of power on the morphological structure of the final composite is only presented. The particle morphology and distribution within the polymeric matrix are studied by TEM (Figure 9). These images confirm the presence of nanostructures on the surface of all composites. Round shaped silver nanoparticles are observed for pp-AAl synthesized at the lowest power with a homogeneous distribution whose mean size is around $7 \mathrm{~nm}$. When pp-AAl is elaborated at higher power, a larger distribution of metal particles is observed indicating the agglomeration of silver nanoparticles which are moreover, inhomogeneously distributed on the polymer. Two types of population are observed: one, the most important, whose average diameter is around $9 \mathrm{~nm}$ and the other, with an average diameter of around $25 \mathrm{~nm}$.

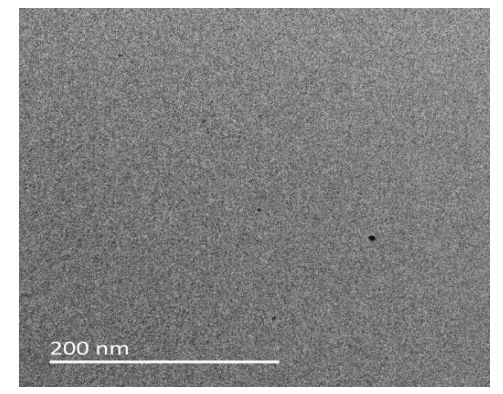

(a)

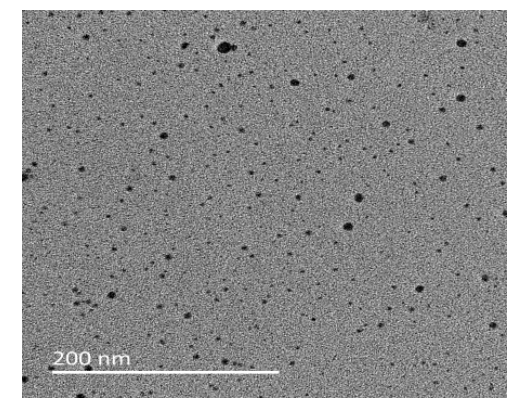

(b)

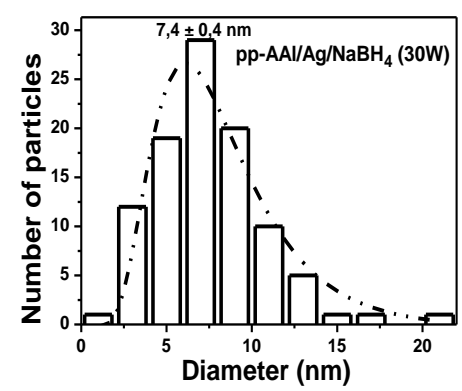

(d)

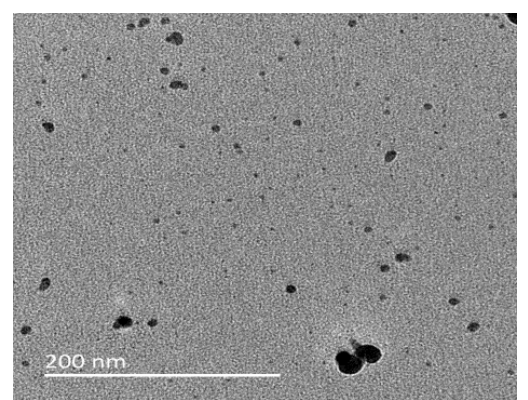

(c)

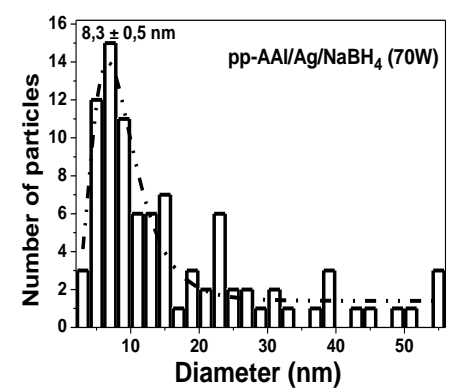

(e)

Figure 9. (a) TEM image of pp-AAl, (b), (d) TEM image and particles distribution of pp$\mathrm{AAl} / \mathrm{Ag} / \mathrm{NaBH}_{4}$ synthesized at $(P=30 \mathrm{~W}$, ton $=17 \mu \mathrm{s})$, and (c), (e) TEM image and particles distribution of pp-AAl/Ag/NaBH 4 synthesized at $(P=70 \mathrm{~W}$, ton $=17 \mu \mathrm{s})$. 
In conclusion, the mildest plasma conditions (low power and discharge time) are the best conditions for the synthesis of the polymer matrix allowing the inclusion of a higher amount of metal with a homogeneous distribution and size.

\subsection{Influence of the nature of the metal on the final polymer/metal composite}

\subsubsection{Metal interaction}

In a first time, the amount of each metal has been quantified using XPS in the plasma polymer matrix after impregnation in the metal salts and reduction with $\mathrm{NaBH}_{4}$ (Figure 10).

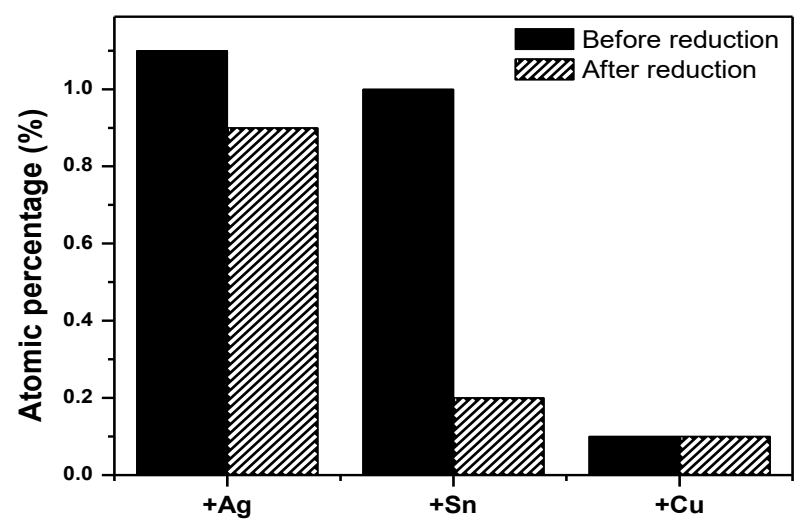

Figure 10. XPS quantification of metals in pp-AAl $(P=30 \mathrm{~W}$, ton $=17 \mu \mathrm{s})$ after impregnation and reduction.

This graph clearly shows the decrease of the metal amount in the polymer after dipping in the reducing solution. This loss of metal ions into $\mathrm{NaBH}_{4}$ aqueous solution is due to ion exchange between $\mathrm{Na}^{+}$in the solution and $\mathrm{Ag}^{+}, \mathrm{Cu}^{(2)+}$ or $\mathrm{Sn}^{2+}$ in the polymer. ${ }^{25}$ In fact, $\mathrm{M}^{\mathrm{n}+}$ ions are bound to pp-AAl via electrostatic interactions (ion-dipole), as explained before. As we see in the case of $\mathrm{Ag}$ and $\mathrm{Cu}$, a small percentage decreases after the reduction step (around $20 \%$ for $\mathrm{Ag}^{+}$), due to the reduction of the majority of metal ions to the metallic state by pp-AAl even before adding 
$\mathrm{NaBH}_{4}$ (Figure 11). In contrast to $\mathrm{Sn}^{2+}$ ions, which are not reduced by the matrix due to their redox potential too close to that of the polymer and that remains in its ionic form as shown in Figure 11. It thus facilitates the loss of $80 \%$ of $\mathrm{Sn}^{2+}$ into the $\mathrm{NaBH}_{4}$ solution.

Before the reduction step, the $\mathrm{Ag} 3 \mathrm{~d}_{5 / 2}$ peak envelop is decomposed into two component peaks at $366.6 \mathrm{eV}$ and $368.5 \mathrm{eV}$, which correspond to two different states of silver, namely silver oxide $\left(\mathrm{Ag}^{+}, 2.8 \%\right)$ and metallic silver $\left(\mathrm{Ag}^{0}, 97.2 \%\right)$, respectively (Figure 11a). ${ }^{13,26}$ After the reduction step, only one component is obtained at $368.5 \mathrm{eV}$ indicating the complete reduction to the metallic state. Two components for copper spectra are observed, one at $933 \mathrm{eV}$ attributed to the copper species in the oxidation state $\mathrm{Cu}^{+} / \mathrm{Cu}^{\circ}(70.1 \%$ before and $85.6 \%$ after reduction, respectively) $)^{5,27-31}$ and another one at $934.8 \mathrm{eV}$ attributed to $\mathrm{Cu}^{2+}(29.9 \%$ before and $14.4 \%$ after reduction, respectively) ${ }^{32}$ (Figure 11b). This incomplete reduction can be attributed to the oxidation phenomenon which is faster than in the case of silver. While the XPS high-resolution spectra of $\mathrm{Sn} 3 \mathrm{~d}_{5 / 2}$ indicates the presence of a single peak at $487 \mathrm{eV}$ before and after $\mathrm{NaBH}_{4}$ reduction, attributed to $\mathrm{Sn}^{2+/ 4+33,34}$ (Figure 11c). The absence of a peak at $485.5 \mathrm{eV}$ assigned to metallic tin, is probably related to the fast oxidation of Sn nanoparticles. ${ }^{35}$ All these results show that Sn oxidizes quickly, contrary to $\mathrm{Cu}$, and $\mathrm{Ag}$ that hardly oxidizes.

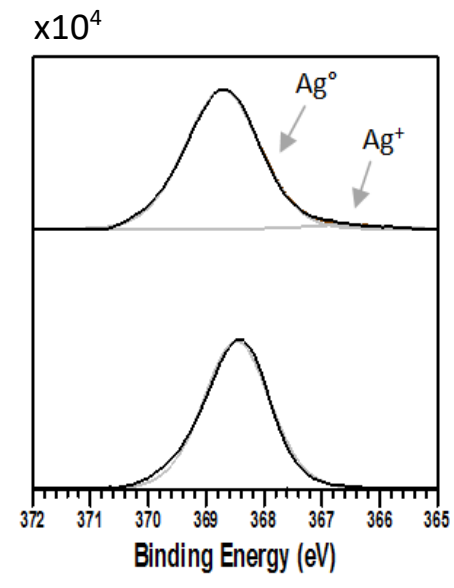

(a)

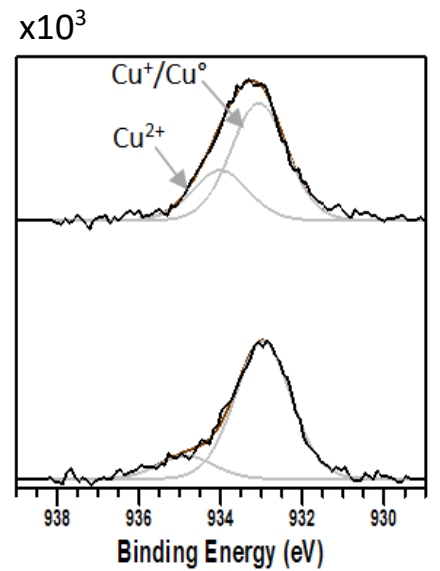

(b)

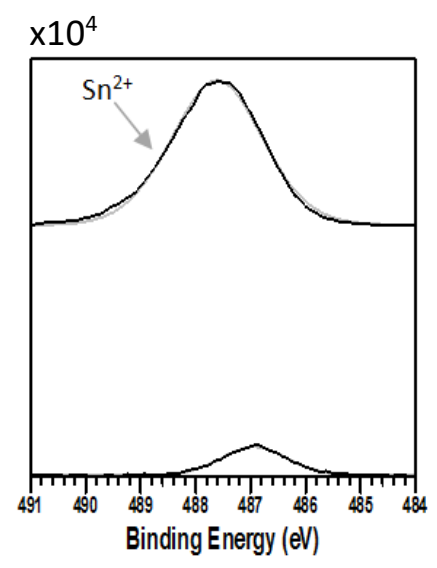

(c)

Figure 11. High resolution XPS spectra of (a) $\mathrm{Ag} 3 \mathrm{~d}_{5 / 2}$, (b) $\mathrm{Cu} 2 \mathrm{p}_{3 / 2}$ and (c) $\mathrm{Sn} 3 \mathrm{~d}_{5 / 2}$. 
Figure 10 shows also the small amount of copper ions introduced into the polymer matrix contrary to silver and tin ions. Indeed, the percentages of silver and tin are quite similar, of about 1.1 and $1 \%$, respectively, whereas copper is less than $0.1 \%$. This result can be attributed to the differences in electronic structure of these metals, since silver and tin are $4 \mathrm{~d}$ metals, whereas copper is a $3 \mathrm{~d}$ metal. ${ }^{36,37}$

\subsubsection{Metal distribution}

Figure 12 shows the TEM images of the metal repartition on pp-AAl. It reveals less surface coverage of $\mathrm{Cu}$ compared to $\mathrm{Ag}$ and $\mathrm{Sn}$ with a good agreement with XPS results following the small amount of it.

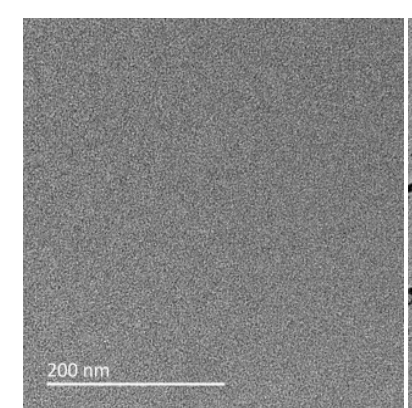

(a)

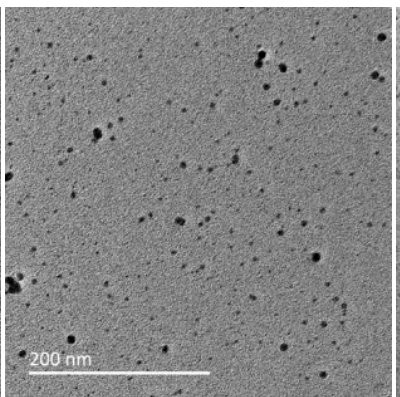

(b)

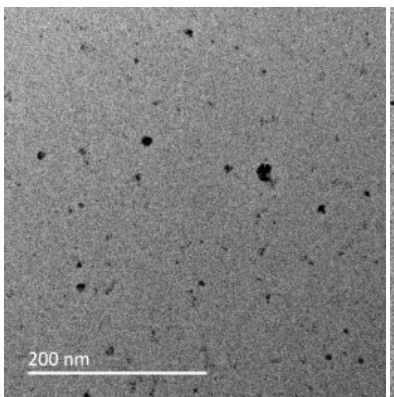

(c)

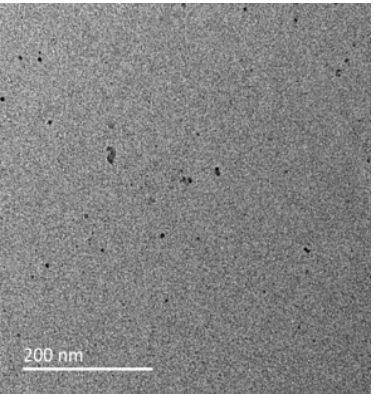

(d)

Figure 12. TEM images of pp-AAl before (a) and after impregnation in the different metallic solutions and the reduction step: (b) $\mathrm{Ag}$, (c) $\mathrm{Sn},(\mathrm{d}) \mathrm{Cu}$.

It is also observed that the distribution of spherical Ag nanoparticles is uniform throughout the polymer matrix compared to the spherical structures of $\mathrm{Sn}$ and $\mathrm{Cu}$ which are randomly distributed in the polymer.

\section{Conclusion}


In this work, we have elaborated different $\mathrm{pp}-\mathrm{AAl} / \mathrm{metal}$ nanocomposites by varying the chemical structure of the plasma polymer and the nature of the metal. We have shown that the amount of loaded metal is high and homogeneously distributed when the polymer matrix surface is rough (high deposition time) and contains a high amount of hydroxyl groups (low discharge power and on-time). The nature of the metal has also a strong influence on its embedded amount and distribution in the matrix. Indeed, a higher amount of silver and tin ions is inserted compared to copper which is probably related to the electronic structure of the metal. Finally, the impregnation in the metal salt solution and the chemical reduction must be done in two steps rather than in one step in order to form an homogeneous monodisperse polymer/metal structure with a high amount of metal.

\section{References}

1. Sadhir RK. Deposition of conducting thin films of organometallic monomers by plasma polymerization. J Vac Sci Technol A Vacuum, Surfaces, Film. 1985;3(6):2093. doi:10.1116/1.572930.

2. Körner E, Aguirre MH, Fortunato G, Ritter A, Rühe J, Hegemann D. Formation and distribution of silver nanoparticles in a functional plasma polymer matrix and related Ag+ release properties. Plasma Process Polym. 2010;7(7):619-625. doi:10.1002/ppap.200900163.

3. Saulou C, Despax B, Raynaud P, et al. Plasma-Mediated Nanosilver-Organosilicon Composite Films Deposited on Stainless Steel: Synthesis, Surface Characterization, and Evaluation of Anti-Adhesive and Anti-Microbial Properties on the Model Yeast Saccharomyces cerevisiae. Plasma Process Polym. 2012;9(3):324-338. doi:10.1002/ppap.201100033.

4. Heilmann a, Werner J. In situ observation of microstructural changes of embedded silver 
particles. Thin Solid Films. 1998;317(1-2):21-26. doi:10.1016/S0040-6090(97)00499-9.

5. Wagner AJ, Wolfe GM, Fairbrother DH. Reactivity of vapor-deposited metal atoms with nitrogen-containing polymers and organic surfaces studied by in situ XPS. Appl Surf Sci. 2003;219(3-4):317-328. doi:10.1016/S0169-4332(03)00705-0.

6. Ramesh G V, Porel S, Radhakrishnan TP. Polymer thin films embedded with in situ grown metal nanoparticles. Chem Soc Rev. 2009;38(9):2646. doi:10.1039/b815242j.

7. Rifai S, Breen CA, Solis DJ, Swager TM. Facile in situ silver nanoparticle formation in insulating porous polymer matrices. Chem Mater. 2006;18(1):21-25. doi:10.1021/cm0511419.

8. Silva AMB, de Araújo CB, Santos-Silva S, Galembeck A. Silver nanoparticle in situ growth within crosslinked poly(ester-co-styrene) induced by UV irradiation: aggregation control with exposure time. J Phys Chem Solids. 2007;68(5-6):729-733. doi:10.1016/j.jpcs.2007.03.052.

9. Li J, Kamata K, Watanabe S, Iyoda T. Template- And vacuum-ultraviolet-assisted fabrication of a Ag-nanoparticle array on flexible and rigid substrates. Adv Mater. 2007;19(9):1267-1271. doi:10.1002/adma.200602851.

10. Zhang J, Gao Y, Alvarez-Puebla RA, Buriak JM, Fenniri H. Synthesis and SERS Properties of Nanocrystalline Gold Octahedra Generated from Thermal Decomposition of HAuCl4 in Block Copolymers. Adv Mater. 2006;18(24):3233-3237. doi:10.1002/adma.200601368.

11. Horiuchi S, Nakao Y. Polymer/metal nanocomposites: Assembly of metal nanoparticles in polymer films and their applications. Curr Nanosci. 2007;3(3):206-214.

12. Vasilev K, Sah V, Anselme K, et al. Tunable antibacterial coatings that support mammalian cell growth. Nano Lett. 2010;10(1):202-207. doi:10.1021/n1903274q.

13. Kumar V, Jolivalt C, Pulpytel J, Jafari R, Arefi-Khonsari F. Development of silver 
nanoparticle loaded antibacterial polymer mesh using plasma polymerization process. $J$ Biomed Mater Res - Part A. 2013;101 A(4):1121-1132. doi:10.1002/jbm.a.34419.

14. Airoudj A, Ploux L, Roucoules V. Effect of plasma duty cycle on silver nanoparticles loading of cotton fabrics for durable antibacterial properties. J Appl Polym Sci. 2015;132(1):n/a-n/a. doi:10.1002/app.41279.

15. Krishnamurthy V, Kamel IL. Argon plasma treatment of glass surfaces. J Mater Sci. $1989 ; 24: 3345-3352$.

16. Terpilowski K, Rymuszka D. Surface properties of glass plates activated by air, oxygen, nitrogen and argon plasma. Glas Phys Chem. 2016;42(6):535-541. doi:10.1134/S1087659616060195.

17. Shameli K, Ahmad M Bin, Jazayeri SD, Shabanzadeh P, Sangpour P. Investigation of antibacterial properties silver nanoparticles prepared via green method. 2012:1-10. doi:10.1186/1752-153X-6-73.

18. Potapov AL, Daineko OA, Ivanova NA, Agabekov VE, Bin-Hussain M. Formation and properties of films based on polyvinyl alcohol and doped with silver nanoparticles. Appl Surf Sci. 2015;350:121-128. doi:10.1016/j.apsusc.2015.02.149.

19. Abbaszadegan A, Ghahramani Y, Gholami A, et al. The Effect of Charge at the Surface of Silver Nanoparticles on Antimicrobial Activity against Gram-Positive and GramNegative Bacteria : A Preliminary Study. 2015;2015.

20. Šileikaitė A, Prosyčevas I, Puišo J, Juraitis A, Guobienė A. Analysis of Silver Nanoparticles Produced by Chemical Reduction of Silver Salt Solution. Mater Sci. 2006;12(4):1392-1320. doi:10.1002/jid.

21. Henglein A. Physicochemical properties of small metal particles in solution: "Microelectrode" reactions, chemisorption, composite metal particles, and the atom-tometal transition. J Phys Chem. 1993;97(21):5457-5471. doi:10.1021/j100123a004. 
22. Yu D-G. Formation of colloidal silver nanoparticles stabilized by Na+-poly $(\gamma$-glutamic acid)-silver nitrate complex via chemical reduction process. Colloids Surfaces B Biointerfaces. 2007;59(2):171-178. doi:10.1016/j.colsurfb.2007.05.007.

23. Fahmy A, Friedrich J, Poncin-Epaillard F, Debarnot D. Plasma polymerized allyl alcohol/O2 thin films embedded with silver nanoparticles. Thin Solid Films. 2016;616:339-347. doi:10.1016/j.tsf.2016.08.045.

24. Fahmy A, Schönhals A, Friedrich J. Reaction of Water with (Radicals in) Plasma Polymerized Allyl Alcohol (and Formation of OH-Rich Polymer Layers). J Phys Chem B. 2013;117(36):10603-10611. doi:10.1021/jp406186x.

25. He J, Ichinose I, Kunitake T, Nakao A. In Situ Synthesis of Noble Metal Nanoparticles in Ultrathin TiO $2-$ Gel Films by a Combination of Ion-Exchange and Reduction Processes. Langmuir. 2002;18(25):10005-10010. doi:10.1021/la0260584.

26. Ajitha B, Ashok Kumar Reddy Y, Sreedhara Reddy P. Green synthesis and characterization of silver nanoparticles using Lantana camara leaf extract. Mater Sci Eng C. 2015;49:373-381. doi:10.1016/j.msec.2015.01.035.

27. Cioffi N, Torsi L, Ditaranto N, et al. Copper nanoparticle/polymer composites with antifungal and bacteriostatic properties. Chem Mater. 2005;17(21):5255-5262. doi:10.1021/cm0505244.

28. Biesinger MC, Payne BP, Grosvenor AP, Lau LWM, Gerson AR, Smart RSC. Resolving surface chemical states in XPS analysis of first row transition metals, oxides and hydroxides: Cr, Mn, Fe, Co and Ni. Appl Surf Sci. 2011;257(7):2717-2730. doi:10.1016/j.apsusc.2010.10.051.

29. Kredl J, Kolb JF, Schnabel U, Polak M, Weltmann KD, Fricke K. Deposition of antimicrobial copper-rich coatings on polymers by atmospheric pressure jet plasmas. Materials (Basel). 2016;9(4). doi:10.3390/ma9040274. 
30. Akamatsu T, Ichikawa S, Okudaira S, et al. Introduction of an examination and treatment for Helicobacter pylori infection in high school health screening. J Gastroenterol. 2011;46(12):1353-1360. doi:10.1007/s00535-011-0450-6.

31. Ahmed A, Robertson CM, Steiner A, et al. $\mathrm{Cu}(\mathrm{i}) \mathrm{Cu}(\mathrm{ii}) \mathrm{BTC}$, a microporous mixedvalence MOF via reduction of HKUST-1. RSC Adv. 2016;6(11):8902-8905. doi:10.1039/C5RA23754H.

32. Kaushik VK. TOPICS IN SURFACE AND DEPTH PROFILE ANALYSIS Identification of oxidation states of copper in mixed oxides and chlorides using ESCA *' t. 1988;(148).

33. Arun B, Loffeld A. Long-standing hidradenitis suppurativa treated effectively with metformin. Clin Exp Dermatol. 2009;34(8):920-921. doi:10.1111/j.13652230.2008.03121.x.

34. Zhong X, Zhang G, Qiu Y, Chen Z, Guo X, Fu C. The corrosion of tin under thin electrolyte layers containing chloride. Corros Sci. 2013;66:14-25. doi:10.1016/j.corsci.2012.08.040.

35. Zavyalov SA, Pivkina AN, Schoonman J. Formation and characterization of metalpolymer nanostructured composites. Solid State Ionics. 2002;147(3-4):415-419. doi:10.1016/S0167-2738(02)00038-3.

36. Kharlamova M V. Comparison of influence of incorporated 3d-, 4d- and 4f-metal chlorides on electronic properties of single-walled carbon nanotubes. Appl Phys A. 2013;111(3):725-731. doi:10.1007/s00339-013-7639-х.

37. Kharlamova M V., Niu JJ. Comparison of metallic silver and copper doping effects on single-walled carbon nanotubes. Appl Phys A Mater Sci Process. 2012;109(1):25-29. doi:10.1007/s00339-012-7091-3. 